\title{
Identification of Yersinia at the Species and Subspecies Levels Is Challenging
}

\section{Fredriksson-Ahomaa, Maria Ulrika Kristina} 2018

Fredriksson-Ahomaa , M U K , Joutsen , S O \& Laukkanen-Ninios , R K 2018 , ' Identification of Yersinia at the Species and Subspecies Levels Is Challenging ', Current clinical microbiology reports , vol. 5 , no. 2 , pp. 135-142 . https://doi.org/10.1007/s40588-018-0088-8

http://hdl.handle.net/10138/309550

https://doi.org/10.1007/s40588-018-0088-8

acceptedVersion

Downloaded from Helda, University of Helsinki institutional repository.

This is an electronic reprint of the original article.

This reprint may differ from the original in pagination and typographic detail.

Please cite the original version. 
1 Identification of Yersinia at the species and subspecies levels is challenging 2

3 Maria Fredriksson-Ahomaa ${ }^{1 *}$, Suvi Joutsen ${ }^{1,2}$, Riikka Laukkanen-Ninios ${ }^{1,2}$

$4{ }^{1}$ Faculty of Veterinary Medicine, P.O.Box 66, 00014 University of Helsinki, Finland

$5 \quad{ }^{2}$ Finnish Food Safety Authority Evira, Mustialankatu 3, 00790 Helsinki, Finland

6

7 *maria.fredriksson-ahomaa@helsinki.fi 


\section{Abstract}

9

10 The genus Yersinia currently includes 18 species, of which $Y$. enterocolitica and $Y$.

11 pseudotuberculosis are enteropathogenic. The identification of $Y$. enterocolitica in particular is very

12 demanding, because it consists of a group of very heterogeneous bacteria, including pathogenic and

13 non-pathogenic strains. The aim of the review is to provide recent information on the characteristics

14 and identification of Yersinia spp. and sources of enteropathogenic Yersinia spp. Identification of

15 Yersinia spp. is still mainly based on biochemical tests and serotyping, but molecular methods have

16 increasingly also been used. Sequencing the whole genome enables more accurate identification of

17 enteropathogenic Yersinia spp. Pathogenic Y. enterocolitica strains of different bioserotypes have

18 newly been identified from various animal sources. Moreover, the virulence gene ail has been

19 detected in non-pathogenic Yersinia strains, especially from wild animals. Correct identification of

20 pathogenic Yersinia strains is essential in assessing the health risk for humans and animals.

21

22 Keywords Yersinia $\cdot$ taxonomy $\cdot$ characteristics $\cdot$ identification $\cdot$ subtyping $\cdot$ sources 


\section{Introduction}

The genus Yersinia is large and diverse, currently consisting of 18 species (1•). The enteropathogenic Yersinia spp., Y. enterocolitica and Y. pseudotuberculosis are important foodborne pathogens, mostly causing self-limiting enteritis in humans and an asymptomatic infection in animals $(1 \cdot 2)$. Human and animal cases are mainly sporadic and outbreaks are rare (3.). Human yersiniosis is usually due to $Y$. enterocolitica, and is still the third most commonly reported enteritis in Europe, thus the correct identification of these enteropathogenic Yersinia is essential for making correct diagnoses, and for preventing new infections (4). However, identification of Yersinia to the species and subspecies levels can be very demanding, especially the identification of pathogenic $Y$. enterocolitica (5•). Y. enterocolitica is a very heterogeneous species including six biotypes and phylogenetic groups varying from non-pathogenic to highly pathogenic strains $(6,7)$. Y. enterocolitica and Y. pseudotuberculosis are widely found in various animal species. However, pathogenic $Y$. enterocolitca strains have mostly been isolated from pigs at slaughter $(2,3 \cdot)$.

\section{Taxonomy of the genus Yersinia}

The taxonomy of genus Yersinia, which belongs to the family Enterobacteriaceae, has experienced wide changes over the years (8-10). Presently it comprises 18 species (Y. aldovae, Y. aleksiciae, $Y$. bercovieri, Y. entomophaga, Y. enterocolitica, Y. frederiksenii, Y. intermedia, Y. kristensenii, $Y$. massiliensis, Y. mollaretii, Y. nurmii, Y. pekkanenii. Y. pestis, Y. pseudotuberculosis, $Y$. rohdei, $Y$. ruckeri, $Y$. similis and $Y$. wautersii) $(1 \cdot, 3 \cdot, 11)$. Enteropathogenic $Y$. enterocolitica and $Y$. pseudotuberculosis together with plague-associated $Y$. pestis are the three species virulent for humans and animals, $Y$. ruckeri is a fish pathogen, $Y$. entomophaga is an insect pathogen and the rest are more or less environmental species rarely associated with human or animal diseases (5•). $Y$. 
wautersii is the latest species that formed a clearly distinct non-pathogenic population of strains in the $Y$. pseudotuberculosis complex group; however, Neubauer and Sprague (12) claimed that $Y$. wautersii should continue to be classified as the $Y$. pseudotuberculosis complex and not as a separate species. $Y$. nurmii and $Y$. entomophaga have recently been reported to be very closely related (13). Y. enterocolitica species is a very heterogeneous group of bacteria including both pathogenic and non-pathogenic strains (5•). Currently, $Y$. enterocolitica is divided into two subspecies based on the 16S rRNA gene sequence: subsp. enterocolitica including high-pathogenic strains and subsp. palearctica including low-pathogenic and non-pathogenic strains. However, it appears that European non-pathogenic $Y$. enterocolitica strains form at least one own subspecies $(14,15)$. Moreover, Sihvonen et al. (16) presented two different phylogenetic clusters of $Y$. enterocolitica 1A strains based on seven housekeeping genes (Table 1). Using whole-genome sequencing, $Y$. enterocolitica species has newly been divided into six phylogenetic groups $(5 \cdot)$.

\section{Characteristics of Yersinia spp.}

Members of Yersinia spp. are gram negative, facultative anaerobic rod-shaped bacterium (8). The size of complete Yersinia genomes, except $Y$. ruckeri, which is clearly smaller, range from 4.0 to 4.9 $\mathrm{Mb}$ with $\mathrm{G}+\mathrm{C}$ contents ranging from 47 to $49 \%$ (www.ncbi.nlm.nih.gov/genome/). Yersinia bacteria are psychrotrophic and thus capable of growing at low temperatures below $6^{\circ} \mathrm{C}(2)$. Cold enrichment at $4^{\circ} \mathrm{C}$ for one to three weeks has been widely used to isolate Yersinia from clinical, food and environmental samples $(2,17,18)$. Yersinia spp. tolerate freezing for a longer time, but are heat-sensitive. They also tolerate alkaline conditions better than many other bacteria, and thus alkali treatment with potassium hydroxide $(\mathrm{KOH})$ has been used to reduce the level of other bacteria during Yersinia isolation $(17,18)$. Most Yersinia spp., including the two enteropathogenic species $Y$. enterocolitica and Y. pseudotuberculosis, are urease-positive (10). Urea testing is widely used for 
confirmation of suspected enteropathogenic Yersinia colonies (17-19). Yersinia strains are typically resistant to beta-lactam antibiotics due to beta-lactamase genes located in the chromosome (20). However, $Y$. pseudotuberculosis strains are usually susceptible to tested antimicrobials while $Y$. enterocolitica strains are more often resistant (19). Resistance to streptomycin, sulphonamide and tetracycline among $Y$. enterocolitica strains has recently been reported in Italy, Spain and Iran $(19,21,22)$. Resistance to chloramphenicol, ciprofloxacin, nalidixic acid and sulfamethoxazoletrimethoprim has also been shown (19-22).

The three human pathogenic Yersinia spp. (Y. enterocolitica, Y. pseudotuberculosis and Y. pestis) carry the approximately 70-kb virulence plasmid (pYV), which is essential for their survival and ability to multiply in different lymphoid tissues of the host $(1,10,23)$. All correctly identified $Y$. pseudotuberculosis strains are considered pathogenic whereas $Y$. enterocolitica sp. also includes non-pathogenic strains not carrying the pYV $(1,3)$. The high pathogenicity island HPI is only found in the high-pathogenic $Y$. enterocolitica strains and frequently in $Y$. pseudotuberculosis $0: 1$ and O:3 strains $(2,10,24)$. Some $Y$. pseudotuberculosis strains more commonly found in the Far East can also synthesise a superantigen toxin YPM (Y. pseudotuberculosis -derived mitogen) (25). YPM plays an important role in systemic infections, especially in the disease called Far East scarlet fever (FESLF) primarily observed in Japan and Russia $(25,26)$. Based on the virulence in the mouse model, Y. enterocolitica can be divided into three groups consisting of highly pathogenic, weakly pathogenic and non-pathogenic strains (10). Non-pathogenic $Y$. enterocolitica strains typically lack the chromosomal virulence genes ail and yst $\mathrm{A}$ but carry the $y s t \mathrm{~B}$ gene $(7,21,27)$. Interestingly, the ail gene has also quite recently been detected more frequently in $Y$. enterocolitica biotype $1 \mathrm{~A}$ strains, especially in 1A strains from wildlife, but recently also from sheep and lettuce (12,28-34). Joutsen et al. (29) reported newly ail-positive $Y$. kristensenii strains isolated from voles. 
The two human pathogens, $Y$. enterocolitica and $Y$. pseudotuberculosis, are transmitted faecalorally and colonise the intestinal tract, especially the Peyer's patches in the terminal ileum $(1,10,23,35)$. The clinical picture varies depending on the patient's age and immune system, and the pathogenicity of the strain. The symptoms of $Y$. enterocolitica and $Y$. pseudotuberculosis infections can be quite similar (2). The most common symptoms are diarrhoea and fever, which occur especially in young children $(22,36)$. Both bacteria may produce terminal ileitis and mesenteric lymphadenitis, which are sometimes accompanied with secondary infections, such as reactive arthritis and erythema nodosum, occurring more commonly in adolescents and adults $(22,23,35)$. Human enteropathogenic yersiniosis occurs mostly sporadically, and outbreaks, especially due to $Y$. enterocolitica, are rare $(2,4,37,38) . Y$. pseudotuberculosis outbreaks have more often been reported in Finland, Japan and Russia (2,25). Outbreaks due to $Y$. pseudotuberculosis infection linked to contaminated raw milk and produce have recently been reported in Finland and New Zealand, respectively $(39,40)$. Worldwide, the most common types associated with human infections are $Y$. enterocolitica bioserotypes 2/O:9 and 4/O:3, and $Y$. pseudotuberculosis serotypes $0: 1$ and O:3 (41). The high-pathogenic $Y$. enterocolitica $\mathrm{O}: 8$, which typically belongs to biotype 1B, has newly been identified in sporadic human yersiniosis with varying symptoms in Japan (38).

\section{Identification of Yersinia spp.}

Several selective agar plates have been designed for isolation and identification of Yersinia spp. from different sources $(17,42)$. CIN (cefsulodin-irgasan-novobiocin) agar plates are still mostly used for Yersinia isolation $(7,17,18,43)$. However, this medium is not optimal for all pathogenic strains such as $Y$. enterocolitica biotype 3 strains and some $Y$. pseudotuberculosis strains. Furthermore, pathogenic strains sometimes grow as very small colonies missing the typical red centre on the CIN plates $(18,42)$. Chromogenic-based agar plates have become popular in recent 
years for isolation and identification of $Y$. enterocolitica belonging to pathogenic biotypes (42).

124 CHROMagar Yersinia (CAY), which is currently the only commercial chromogenic medium, is not

125

126

127 suitable for $Y$. pseudotuberculosis isolation $(2,43)$. Tan et al. (42) recently designed a modified CIN agar plate that provided a better discrimination of Yersinia colonies from other bacteria than traditional CIN agar. A stereomicroscope has been used to aid in the identification of characteristic Yersinia colonies on selective agar plates for further confirmation $(17,18)$.

Yersinia spp. are still mostly identified by commercial biochemical identification systems like API20E, API50CH, Microgen ${ }^{\mathrm{TM}}$ GN-ID and Biolog Microbial ID (3,19,44-46). However, biochemical reactions do not guarantee reliable identification at species level, as only minor differences often exist between species $(1,2,46,47)$. Especially, non-pathogenic Yersinia spp. are difficult to differentiate from $Y$. enterocolitica, and $Y$. similis and $Y$. wautersii similarly from $Y$. pseudotuberculosis $(12,47)$. Joutsen et al. (29) recently reported that differentiating between sucrose-negative $Y$. enterocolitica and $Y$. kristensenii and identification of $Y$. pseudotuberculosis is impossible when only using API20E. Furthermore, identification of bioserotype 5/O:(1,2,)3 strains isolated from sheep is very challenging (30).

Identification of Yersinia spp. by matrix-assisted laser desorption/ionisation time-of-flight (MALDI-TOF) mass spectrophotometry has emerged as a rapid and accurate technology that provides protein profiles for the identification of Yersinia at the species and subspecies levels (33,48-52). Rizzardi et al. (49) designed a protocol that was able to correctly identify the common pathogenic bioserotypes 2/O:9, 2/O:5,27 and 4/O:3. However, biochemical methods are still needed to distinguish non-pathogenic biotype 1A strains from highly pathogenic 1B strains. Differentiation between $Y$. pseudotuberculosis, $Y$. pestis and $Y$. similis is also challenging due to their tight genetic 
147 relationship (48). Thus, comprehensive databases are needed, and additional confirmatory testing in 148 some cases as well.

Methods based on sequencing are more accurate for identifying Yersinia spp. than methods based

151

152

153

154

155

on phenotypic characteristics (2). 16SrRNA gene sequencing is widely used for investigation of taxonomic relationships including species identification; however, in many bacterial species including Yersinia spp., the 16SrRNA gene sequences show high similarity and lack enough variation to differentiate species or subspecies $(46,47)$. Murros et al. (15) recently showed that the discriminatory power of 16SrRNA sequencing is too low to discriminate non-pathogenic $Y$. enterocolitica 1A strains from the pathogenic $Y$. enterocolitica strain belonging to biotypes 2-5. Multilocus sequence analysis (MLSA), which has a higher resolution than 16SrRNA gene sequencing, has widely been used in taxonomic studies to determine phylogenetic relationships of Yersinia strains $(11,15,47,53,54)$. The four housekeeping genes $g \ln \mathrm{A}, g y r \mathrm{~B}, h s p 60$ and $r e c \mathrm{~A}$ based on Kotetishvili et al. (55) have been used in most taxonomic studies of Yersinia spp. $(11,15,53,54)$. In multilocus sequence typing (MLST), sequences of approximately $500 \mathrm{bp}$ of at least seven housekeeping genes have been indexed to identify the sequence type of the studied isolate (56). Seven housekeeping genes according to Hall et al. (5) have mainly been used to characterise $Y$. enterocolitica isolates $(34,57)$ and seven housekeeping genes according to Laukkanen-Ninios et al. (58) for $Y$. pseudotuberculosis isolates $(26,39,59)$ (Table 1). Duan et al. (59) developed an MLST scheme based on the housekeeping genes according to Laukkanen et al. (58) for the three pathogenic Yersinia spp. and Hall et al. (5) developed a pan-Yersinia MLST scheme for accurate and reproducible identification of Yersinia isolates. The sequence data are freely available and the allelic profiles of isolates can be compared to those in central databases (http://enterobase.warwick.ac.uk/species/index/yersinia, https://pubmlst.org/yersinia/). 
172 Serotyping Y. enterocolitica and Y. pseudotuberculosis is still an approach for diagnostics to

173 identify these two pathogens and to assess their potential pathogenicity, especially for $Y$.

174

175 enterocolitica $(8,10)$. Classical serotyping performed by slide agglutination using commercial monovalent and polyvalent sera is very simple and cost-effective, however, several drawbacks exist: interpretation is occasionally challenging and both false-positive and false-negative results may occur. Especially serotypes associated with pathogenicity, such as O:3, O:8 and O:9, may appear among non-pathogenic $Y$. enterocolitica strains and other non-pathogenic Yersinia spp. (27,60). Furthermore, a cross-reaction between serotype O:9 and Brucella occurs $(61,62)$. Recently Garzetti et al. (27) designed a PCR-based typing scheme for identifying Y. enterocolitica serotypes $\mathrm{O}: 3, \mathrm{O}: 5,27, \mathrm{O}: 8$ and O:9, which are the most common serotypes associated with human and animal diseases. In a recent study, Bozcal et al. (51) used PCR-based O-antigen genotyping and serotypespecific bacteriophages for identification of $Y$. enterocolitica serotypes O:3, O:5,27 and O:9.

Biotyping based on a series of biochemical reactions is still widely used for $Y$. enterocolitica because biotypes correlate with the potential pathogenicity of this species $(3,7,8)$. Strains of biotypes $1 \mathrm{~B}$ and 2 to 5 , which are associated with yersiniosis, carry the virulence plasmis (pYV) and chromosomal virulence genes ail and yst A (27). Biotype 1A strains, which are considered nonpathogenic, lack the pYV and usually carry ystB (60). However, biotyping can be very demanding due to untypical biochemical reactions (5). Recently, six phylogroups (PG) of Y. enterocolitica strains have been proposed using whole genome sequencing $(5,14)$. PG1 consists of the nonpathogenic biotype 1A strains, PG2 of highly pathogenic biotype 1B strains and PG3-PG6 include low-pathogenic strains due to their lethality in a mouse model (5). Alenizi et al. (63) have recently demonstrated that PG1 strains exhibit high levels of virulence in an insect infection model, and thus should no longer be described as non-pathogenic strains. There is also a close association between bioserotype and the source of the strain $(6,7)$. 
198 PCR methods permit rapid identification of pathogenic Yersinia strains with high specificity (27).

199 For pathogenicity, pYV-encoded targets, such as yadA and $\operatorname{vir} \mathrm{F}$, and chromosomal target genes ail 200 and $y$ st A are widely used $(19,20,36,51,64)$. Species-specific regions of virulence genes have also 201 been used for correct identification of enteropathogenic Yersinia (29). The new ISO method uses ail 202 PCR to identify pathogenic $Y$. enterocolitica on selective agar plates before further confirmation 203 (18). However, ail has frequently been detected in Y. enterocolitica biotype 1A strains isolated from 204 wildlife, but also recently in lettuce, and this gene should therefore not be used alone in PCR 205 detection when searching for pathogenic strains $(28,29,31)$.

207 Enteropathogenic Yersinia spp. in animal sources

Culturing, PCR detection and immunoassays have been applied to identify pathogenic $Y$. enterocolitica and $Y$. pseudotuberculosis in clinical, food and environmental samples, and serological analyses have widely been used for indirect detection of enteropathogenic Yersinia in asymptomatic animals, especially in fattening pigs but also recently in wild boars $(2,19,41,45,65$ 68). Serological tests have also proven valuable, especially when enteropathogenic Yersinia has not been identified from the faeces of a patient with sequelae, such as arthritis, after gastroenteritis (69).

Domestic pigs and wild boar have shown to be important reservoirs for pathogenic $Y$. enterocolitica and $Y$. pseudotuberclosis $(3,32,65,66,70)$. Bioserotype 4/O:3 of $Y$. enterocolitica is still the dominant type identified in tonsils, faeces, mandibular lymph nodes and on the carcasses of slaughter pigs (19,36,71-73) (Table 2). Surprisingly, this type has also newly been identified in pigs and humans in West Africa (36). Bioserotype 4/O:3 strains have also been found in pork, which appears to be an important infection source for human infections $(3,74)$. In Asia, Y. enterocolitica 
O:3 strains are commonly identified in pigs and dogs, however, these strains mostly belong to biotype 3 (32). Interestingly, bioserotype 3/O:3 has also newly been identified for the first time in pet hamsters in Japan (75). Bozcal et al. (51) recently found bioserotypes 2/O:5,27 and 2/O:9 in pig manure in Turkey, indicating that pigs may also be a reservoir for these types. $Y$.

pseudotuberculosis $\mathrm{O}: 1$ and O:3 are the most common serotypes identified in human infections in Europe, and the same types have newly been reported by Bonardi et al. (19) in pig tonsils in Italy. In wild boar, a great variety of serotypes have been identified. $Y$. enterocolitica bioserotypes 2/O:5,29, 2/O:9 and 4/O:3, and Y. pseudotuberculosis O:1 and O:2 have been found in Switzerland (76). Recently, Bancerz-Kisiel et al. (28) identified Y. enterocolitica 4/O:3 in wild boars in Poland and Arrausi-Subiza et al. (65) Y. pseudotuberculosis O:1 in northern Spain.

Enteropathogenic Yersinia have been found in domestic ruminants only sporadically (3) (Table 2). Recently, Yang et al. (77) reported quite high prevalence (15\%) of enteropathogenic Yersinia including both $Y$. enterocolitica and Y pseudotuberculosis in sheep tonsils in Austria using PCR detection. $Y$. enterocolitica bioserotype $2 / \mathrm{O}: 9$, which is the second most common type after bioserotype 4/O:3 in human infections, has recently been identified in sheep in Finland (30). In the same study, bioserotype 5/O:(1,2,)3, was found for the first time in Finnish sheep. This rare bioserotype has previously been associated with wild hares in Europe (3). In Ireland and Poland, $Y$. enterocolitica $0: 9$ has frequently been identified in cattle, especially in animals showing falsepositive serological activity to Brucella $(61,62)$. Interestingly, bioserotypes 1B/O:8 and 4/O:3 have been found in raw cow milk in Iran, indicating that cows may also be a reservoir for these types (21). During a $Y$. pseudotuberculosis O:1 outbreak in Finland due to contaminated raw milk, the same serotype was found in both milk and cattle faeces from the same farm (40). $Y$. pseudotuberculosis is a rare finding in cows, but serotypes 0:1-O:3 have sporadically been identified in ruminants in France (3). 
248 Wildlife is an important reservoir of enteropathogenic Yersinia, especially Y.pseudotuberculosis

249 (24). In Italy, Y. pseudotuberculosis O:1 was the most common type identified in wild boar, hare

250 and deer (24). The same type has also newly been identified in brown rats in Belgium (33). $Y$.

251 pseudotuberculosis O:2, which has more frequently been identified in animals than in humans, was

252 recently reported in Finnish shrews $(3,29)$. Pathogenic $Y$. enterocolitica strains have more rarely

253 been identified in wild animals except for wild boars. However, highly pathogenic bioserotype

254 1B/O:8 has recently been identified in wild rodents in Japan (78) and weakly pathogenic

255 bioserotypes 2/O:5,27 and 3/O:1,2,3 in brown rats in Belgium (33). Non-pathogenic $Y$.

256 enterocolitica $1 \mathrm{~A}$ has proven a common finding in wild animals $(29,79)$.

257

$258 Y$. pseudotuberculosis outbreaks have frequently been reported in captive animals, especially in 259 non-human primates (80), but also in captive birds and rodents (44,81-83). Recently, serotype O:1

260 was found in dead Amazonian parrots in Italy (81). Several serotypes have been recently identified 261 in captive animals in Japan: serotypes O:1 and O:4 in squirrel monkeys, serotypes O:2 and O:4 in 262 dead toucans, O:1 in a dead squirrel and O:4 in dead meerkats $(80,82,84)$ (Table 2). In outbreaks 263 with high mortality, $Y$. pseudotuberculosis has shown to be quite easily identified from the spleen 264 and liver using selective CIN agar plates, and biochemical and serological testing $(81,84)$.

\section{Conclusions}

268 Yersiniosis due to $Y$. enterocolitica and $Y$. pseudotuberculosis infections is still the third most 269 frequently reported zoonotic enteric disease in Europe (4). Correct identification of pathogenic

270 Yersinia strains is essential to determine the relevance of the isolated strains in human and animal

271 infections. Biochemical tests are still widely used for identifying Yersinia spp. and for subtyping 
(biotyping) $Y$. enterocolitica strains, although untypical reactions are common and interpretation is demanding. Potential pathogenicity of the strains is mostly confirmed by PCR based on essential virulence genes. In the future, whole genome sequencing with in silico analysis of the data will probably be the best strategy to identify and subtype Yersinia spp.

\section{References}

\section{Papers of particular interest, published recently, have been highlighted as:}

\section{- Of importance}

(1·)McNally A, Thomson NR, Reuter S, Wren BW. 'Add, stir and reduce': Yersinia spp. as model bacteria for pathogen evolution. Nat Rev Microbiol 2016 MAR;14(3):177-190.

(2) Fredriksson-Ahomaa M. Enteropathogenic Yersinia spp. In: Sing A, editor. Zoonoses-Infections affecting humans and animals. 1st ed. London: Springer; 2015. p. 213-234.

(3•) Le Guern A, Martin L, Savin C, Carniel E. Yersiniosis in France: overview and potential sources of infection. Int J Infect Dis 2016 MAY;46:1-7.

(4) EFSA and ECDC. The European Union summary report on trends and sources of zoonoses, zoonotic agents and food-borne outbreaks in 2015. EFSA J 2016;14:4634.

(5•) Hall M, Chattaway MA, Reuter S, Savin C, Strauch E, Carniel E, et al. Use of whole-genus genome sequence data to develop a multilocus sequence typing tool that accurately identifies Yersinia isolates to the species and subspecies levels. J Clin Microbiol 2015 JAN;53(1):35-42.

(6) Fredriksson-Ahomaa M. Chapter 9 - Yersinia enterocolitica. In:

Dodd,C.E.R.,Aldsworth,T.,Stein,R.A.,Cliver,D.O.,Riemann,H.P., editor. Foodborne Diseases. 3rd ed.: Academic Press; 2017. p. 223-233.

(7) Bottone EJ. Yersinia enterocolitica: Revisitation of an enduring human pathogen. Clin Microbiol Newsl 2015;37(1):1-8.

(8) Petersen JM, Gladney LM, Schriefer ME. Yersinia. In: Jorgensen JH, Pfaller MA, Carrol KC, Funke G, Landry ML, Richter SS, et al, editors. Manual of Clinical Microbiology. 11th ed. Washington,DC: ASM Press; 2015. p. 738-751.

(9) Johnson SL, Daligault HE, Davenport KW, Jaissle J, Frey KG, Ladner JT, et al. Thirty-two complete genome assemblies of nine Yersinia species, including Y. pestis, Y. pseudotuberculosis, and Y. enterocolitica. Genome Announc 2015 Apr 30;3(2):10.1128/genomeA.00148-15. 
(10) Rakin A, Garzetti D, Bouabe H, Sprague LD. Yersinia enterocolitica. In: Tang Y, Sussman M, Liu D, Poxton I, Schwartzman J, editors. Molecular Medical Microbiology. 2nd ed.: Elsewier; 2014. p. 1319-1344.

(11) Savin C, Martin L, Bouchier C, Filali S, Chenau J, Zhou Z, et al. The Yersinia pseudotuberculosis complex: Characterization and delineation of a new species, Yersinia wautersii. Int J Med Microbiol 2014 MAY;304(3-4):452-463.

(12) Neubauer H, Sprague LD. Strains of Yersinia wautersii should continue to be classified as the 'Korean Group' of the Yersinia pseudotuberculosis complex and not as a separate species. Int J Syst Evol Microbiol 2015 FEB;65:732-733.

(13) Hurst MRH, Beattie A, Altermann E, Moraga RM, Harper LA, Calder J, et al. The draft genome sequence of the Yersinia entomophaga entomopathogenic type strain MH96T. Toxins 2016 MAY;8(5):143.

(14) Reuter S, Connor TR, Barquist L, Walker D, Feltwell T, Harris SR, et al. Parallel independent evolution of pathogenicity within the genus Yersinia. Proc Natl Acad Sci U S A 2014 MAY 6;111(18):6768-6773.

(15) Murros A, Sade E, Johansson P, Korkeala H, Fredriksson-Ahomaa M, Bjorkroth J. Characterization of European Yersinia enterocolitica 1A strains using restriction fragment length polymorphism and multilocus sequence analysis. Lett Appl Microbiol 2016 OCT;63(4):282-288.

(16) Sihvonen LM, Jalkanen K, Huovinen E, Toivonen S, Corander J, Kuusi M, et al. Clinical isolates of Yersinia enterocolitica biotype 1A represent two phylogenetic lineages with differing pathogenicity-related properties. BMC Microbiol 2012;12:208.

(17) Petsios S, Fredriksson-Ahomaa M, Sakkas H, Papadopoulou C. Conventional and molecular methods used in the detection and subtyping of Yersinia enterocolitica in food. Int J Food Microbiol 2016 NOV 21;237:55-72.

(18) ISO. Microbiology of the food chain - Horizontal method for the detection of pathogenic Yersinia enterocolitica (ISO 10273). ISO 2017:1-47.

(19) Bonardi S, Bruini I, D'Incau M, Van Damme I, Carniel E, Bremont S, et al. Detection, seroprevalence and antimicrobial resistance of Yersinia enterocolitica and Yersinia pseudotuberculosis in pig tonsils in Northern Italy. Int J Food Microbiol 2016 OCT 17;235:125132.

(20) Schneeberger M, Brodard I, Overesch G. Virulence-associated gene pattern of porcine and human Yersinia enterocolitica biotype 4 isolates. Int J Food Microbiol 2015 APR 2;198:70-74.

(21) Jamali H, Paydar M, Radmehr B, Ismail S. Prevalence, characterization, and antimicrobial resistance of Yersinia species and Yersinia enterocolitica isolated from raw milk in farm bulk tanks. J Dairy Sci 2015 FEB;98(2):798-803.

(22) Marimon JM, Figueroa R, Idigoras P, Gomariz M, Alkorta M, Cilla G, et al. Thirty years of human infections caused by Yersinia enterocolitica in northern Spain: 1985-2014. Epidemiol Infect 2017 Aug;145(11):2197-2203. 
(23) Heroven AK, Dersch P. Coregulation of host-adapted metabolism and virulence by pathogenic yersiniae. Front Cell Infect Microbiol 2014 OCT;4:146.

(24) Magistrali CF, Cucco L, Pezzotti G, Farneti S, Cambiotti V, Catania S, et al. Characterisation of Yersinia pseudotuberculosis isolated from animals with yersiniosis during 1996-2013 indicates the presence of pathogenic and Far Eastern strains in Italy. Vet Microbiol 2015 OCT 22;180(12):161-166.

(25) Amphlett A. Far East scarlet-like fever: A review of the epidemiology, symptomatology, and role of superantigenic toxin: Yersinia pseudotuberculosis-derived mitogen A. Open Forum Inf Dis 2016 WIN;3(1).

(26) Timchenko NF, Adgamov RR, Popov AF, Psareva EK, Sobyanin KA, Gintsburg AL, et al. Far East scarlet-like fever caused by a few related genotypes of Yersinia pseudotuberculosis, Russia. Emerg. Infect. Dis., Emerg Infect Dis 2016 MAR;22(3):503-506.

(27) Garzetti D, Susen R, Fruth A, Tietze E, Heesemann J, Rakin A. A molecular scheme for Yersinia enterocolitica patho-serotyping derived from genome-wide analysis. Int J Med Microbiol 2014 MAY;304(3-4):275-283.

(28) Bancerz-Kisiel A, Platt-Samoraj A, Szczerba-Turek A, Syczylo K, Szweda W. The first pathogenic Yersinia enterocolitica bioserotype 4/O:3 strain isolated from a hunted wild boar (Sus scrofa) in Poland. Epidemiol Infect 2015 OCT;143(13):2758-2765.

(29) Joutsen S, Laukkanen-Ninios R, Henttonen H, Niemimaa J, Voutilainen L, Kallio ER, et al. Yersinia spp. in wild rodents and shrews in Finland. Vector-Borne Zoonotic Dis 2017 MAY;17(5):303-311.

(30) Joutsen S, Eklund K, Laukkanen-Ninios R, Stephan R, Fredriksson-Ahomaa M. Sheep carrying pathogenic Yersinia enterocolitica bioserotypes 2/O:9 and 5/O:3 in the feces at slaughter. Vet Microbiol 2016 DEC 25;197:78-82.

(31) Nousiainen L-, Joutsen S, Lunden J, Hänninen M-, Fredriksson-Ahomaa M. Bacterial quality and safety of packaged fresh leafy vegetables at the retail level in Finland. Int J Food Microbiol 2016;232:73-79.

(32) Liang J, Duan R, Xia S, Hao Q, Yang J, Xiao Y, et al. Ecology and geographic distribution of Yersinia enterocolitica among livestock and wildlife in China. Vet Microbiol 2015 JUL 9;178(12):125-131.

(33) Rouffaer LO, Baert K, Van den Abeele A, Cox I, Vanantwerpen G, De Zutter L, et al. Low prevalence of human enteropathogenic Yersinia spp. in brown rats (Rattus norvegicus) in Flanders. PLoS ONE 2017 APR 12;12(4):e0175648.

(34) von Altrock A, Seinige D, Kehrenberg C. Yersinia enterocolitica isolates from wild boars hunted in lower Saxony, Germany. Appl Environ Microbiol 2015 JUL;81(14):4835-4840.

(35) Zinczuk J, Wojskowicz P, Kisluk J, Fil D, Kemona A, Dadan J. Mesenteric lymphadenitis caused by Yersinia enterocolitica. Prz Gastroenterol 2015;10(2):118-121. 
(36) Saraka D, Savin C, Kouassi S, Cisse B, Koffi E, Cabanel N, et al. Yersinia enterocolitica, a neglected cause of human enteric infections in Cote d'Ivoire. PLOS Negl Trop Dis 2017 JAN;11(1):e0005216.

(37) Martin L, Cabanel N, Lesoille C, Menard T, Carniel E. Investigation of an unusual increase in human yersinioses in Creuse, France. Int J Infect Dis 2015 MAY;34:76-78.

(38) Minami K, Yasuda R, Terakawa R, Koike Y, Takeuchi K, Higuchi T, et al. Four sporadic pediatric cases of Yersinia enterocolitica O:8 infection in a rural area of Japan. Jpn J Infect Dis 2017 MAR;70(2):192-194.

(39) Williamson DA, Baines SL, Carter GP, da silva AG, Ren X, Sherwood J, et al. Genomic insights into a sustained national outbreak of Yersinia pseudotuberculosis. Genome Biol Evol 2016 DEC;8(12):3806-3814.

(40) Parn T, Hallanvuo S, Salmenlinna S, Pihlajasaari A, Heikkinen S, Telkki-Nykanen H, et al. Outbreak of Yersinia pseudotuberculosis O:1 infection associated with raw milk consumption, Finland, spring 2014. Eurosurv 2015 OCT 8;20(40):13-19.

(41) Laporte J, Savin C, Lamourette P, Devilliers K, Volland H, Carniel E, et al. Fast and sensitive detection of enteropathogenic Yersinia by immunoassays. J Clin Microbiol 2015 JAN;53(1):146159.

(42) Tan LK, Ooi PT, Carniel E, Thong KL. Evaluation of a modified cefsulodin-irgasannovobiocin agar for isolation of Yersinia spp. PLoS ONE 2014;9(8).

(43) Nguyen Khanh Thuan, Naher K, Kubo R, Taniguchi T, Hayashidani H. Evaluation of chromogenic medium for selective isolation of Yersinia. Food Hyg.Saf.Sci., Food Hyg Safe Sci 2016 OCT;57(5):166-168.

(44) Fogelson SB, Yau W, Rissi DR. Disseminated Yersinia pseudotuberculosis infection in a paca (Cuniculus paca). J Zoo Wildl Med 2015 MAR;46(1):130-134.

(45) Gupta V, Gulati P, Bhagat N, Dhar MS, Virdi JS. Detection of Yersinia enterocolitica in food: an overview. Eur J Clin Microbiol Infect Dis 2015 APR;34(4):641-650.

(46) Hao H, Liang J, Duan R, Chen Y, Liu C, Xiao Y, et al. Yersinia spp. identification using copy diversity in the chromosomal 16S rRNA gene sequence. Plos One 2016 JAN 25;11(1):e0147639.

(47) Merhej V, Adekambi T, Pagnier I, Raoult D, Drancourt M. Yersinia massiliensis sp nov., isolated from fresh water. Int J Syst Evol Microbiol 2008 APR;58:779-784.

(48) Lasch P, Drevinek M, Nattermann H, Grunow R, Stämmler M, Dieckmann R, et al. Characterization of Yersinia using MALDI-TOF mass spectrometry and chemometrics. Anal Chem 2010;82(20):8464-8475.

(49) Rizzardi K, Wahab T, Jernberg C. Rapid subtyping of Yersinia enterocolitica by MatrixAssisted Laser Desorption Ionization-Time of Flight Mass Spectrometry (MALDI-TOF MS) for diagnostics and surveillance. J Clin Microbiol 2013 DEC;51(12):4200-4203. 
(50) Stephan R, Cernela N, Ziegler D, Pflueger V, Tonolla M, Ravasi D, et al. Rapid species specific identification and subtyping of Yersinia enterocolitica by MALDI-TOF Mass spectrometry. J Microbiol Methods 2011 NOV;87(2):150-153.

417

418

419

420

421

422

423

424

425

426

427

428

429

430

431

432

433

434

435

436

437

438

439

440

441

442

443

444

445

446

447

448

(51) Bozcal E, Uzel A, Aydemir S, Skurnik M. Isolation of pathogenic Yersinia enterocolitica strains from different sources in Izmir region, Turkey. Folia Microbiol (Praha) 2015 NOV;60(6):523-529.

(52) Ayyadurai S, Flaudrops C, Raoult D, Drancourt M. Rapid identification and typing of Yersinia pestis and other Yersinia species by matrix-assisted laser desorption/ionization time-of-flight (MALDI-TOF) mass spectrometry. BMC Microbiol 2010;10.

(53) Murros-Kontiainen A, Johansson P, Niskanen T, Fredriksson-Ahomaa M, Korkeala H, Björkroth J. Yersinia pekkanenii sp. nov. Int J Syst Evol Microbiol 2011;61(10):2363-2367.

(54) Murros-Kontiainen A, Fredriksson-Ahomaa M, Korkeala H, Johansson P, Rahkila R, Bjorkroth J. Yersinia nurmii sp nov. Int J Syst Evol Microbiol 2011 OCT;61:2368-2372.

(55) Kotetishvili M, Kreger A, Wauters G, Morris JG, Sulakvelidze A, Stine OC. Multilocus sequence typing for studying genetic relationships among Yersinia species. J Clin Microbiol 2005 JUN;43(6):2674-2684.

(56) Maiden MCJ, Van Rensburg MJJ, Bray JE, Earle SG, Ford SA, Jolley KA, et al. MLST revisited: the gene-by-gene approach to bacterial genomics. Nat Rev Microbiol 2013;11(10):728736.

(57) Rusak LA, Junqueira RM, Hofer E, Vallim DC, Asensi MD. Next-generation sequencing virulome analysis of a Yersinia enterocolitica subsp. palearctica bioserotype 4/O:3 ST18 isolated from human blood in Brazil. Braz J Infect Dis 2017 May 30.

(58) Laukkanen-Ninios R, Didelot X, Jolley KA, Morelli G, Sangal V, Kristo P, et al. Population structure of the Yersinia pseudotuberculosis complex according to multilocus sequence typing. Environ Microbiol 2011;13(12):3114-3127.

(59) Duan R, Liang J, Shi G, Cui Z, Hai R, Wang P, et al. Homology analysis of pathogenic Yersinia species Yersinia enterocolitica, Yersinia pseudotuberculosis, and Yersinia pestis based on multilocus sequence typing. J Clin Microbiol 2014 JAN;52(1):20-29.

(60) Ye Q, Wu Q, Hu H, Zhang J, Huang H. Prevalence and characterization of Yersinia enterocolitica isolated from retail foods in China. Food Contr 2016 MAR;61:20-27.

(61) Szulowski K, Weiner M, Iwaniak W. Occurrence of Yersinia enterocolitica O:9 in feces from cows seropositive for brucellosis. Med Weter 2014 JAN;70(1):42-45.

(62) O'Grady D, Kenny K, Power S, Egan J, Ryan F. Detection of Yersinia enterocolitica serotype $\mathrm{O}: 9$ in the faeces of cattle with false positive reactions in serological tests for brucellosis in Ireland. Vet J 2016 OCT;216:133-135. 
(63) Alenizi D, Ringwood T, Redhwan A, Bouraha B, Wren BW, Prentice M, et al. All Yersinia enterocolitica are pathogenic: virulence of phylogroup $1 Y$. enterocolitica in a Galleria mellonella infection model. Microbiol SGM 2016 AUG;162(8):1379-1387.

(64) Frazao MR, Falcao JP. Genotypic diversity and pathogenic potential of Yersinia enterocolitica biotype 2 strains isolated in Brazil. J Appl Microbiol 2015 APR;118(4):1058-1067.

(65) Arrausi-Subiza M, Gerrikagoitia X, Alvarez V, Ibabe JC, Barral M. Prevalence of Yersinia enterocolitica and Yersinia pseudotuberculosis in wild boars in the Basque Country, northern Spain. Acta Vet Scand 2016 JAN 20;58:4.

(66) Lorencova A, Babak V, Lamka J. Serological prevalence of enteropathogenic Yersinia spp. in pigs and wild boars from different production systems in the Moravian region, Czech Republic. Foodborne Pathog Dis 2016 MAY;13(5):275-279.

(67) Felin E, Jukola E, Raulo S, Fredriksson-Ahomaa M. Meat juice serology and improved food chain Information as control tools for pork-related public health hazards. Zoonoses Public Health 2015;62(6):456-464.

(68) Vanantwerpen G, Van Damme I, De Zutter L, Houf K. Seroprevalence of enteropathogenic Yersinia spp. in pig batches at slaughter. Prev Vet Med 2014 SEP 1;116(1-2):193-196.

(69) Dalby T, Rasmussen E, Schiellerup P, Krogfelt KA. Development of an LPS-based ELISA for diagnosis of Yersinia enterocolitica O:3 infections in Danish patients: a follow-up study. BMC Microbiol 2017 MAY 25;17:125.

(70) Sannö A, Aspán A, Hestvik G, Jacobson M. Presence of Salmonella spp., Yersinia enterocolitica, Yersinia pseudotuberculosis and Escherichia coli O157:H7 in wild boars. Epidemiol Infect 2014;142(12):2542-2547.

(71) Zdolec N, Dobranic V, Filipovic I. Prevalence of Salmonella spp. and Yersinia enterocolitica in/on tonsils and mandibular lymph nodes of slaughtered pigs. Folia Microbiol 2015 MAR;60(2):131-135.

(72) Van Damme I, Berkvens D, Vanantwerpen G, Bare J, Houf K, Wauters G, et al. Contamination of freshly slaughtered pig carcasses with enteropathogenic Yersinia spp.: Distribution, quantification and identification of risk factors. Int J Food Microbiol 2015 JUL 2;204:33-40.

(73) Ibanez TR, Laukkanen-Ninios R, Hakkinen M, Johansson T, Vilar M, Korkeala H. Prevalence of pathogenic Yersinia enterocolitica in finnish slaughter pigs. J Food Protect 2016;79(4):677-681.

(74) Laukkanen-Ninios R, Fredriksson-Ahomaa M, Maijala R, Korkeala H. High prevalence of pathogenic Yersinia enterocolitica in pig cheeks. Food Microbiol 2014 OCT;43:50-52.

(75) Kameyama M, Yabata J, Obane N, Otsuka H, Nomura Y. Detection of pathogenic Yersinia enterocolitica in pet Djungarian hamsters in Japan. J Vet Med Sci 2016 OCT;78(10):1639-1641.

(76) Fredriksson-Ahomaa M, Wacheck S, Bonke R, Stephan R. Different enteropathogenic Yersinia strains found in wild boars and domestic pigs. Foodborne Pathog Dis 2011;8(6):733-737. 
(77) Yang R, Ryan U, Gardner G, Carmichael I, Campbell AJD, Jacobson C. Prevalence, faecal shedding and genetic characterisation of Yersinia spp. in sheep across four states of Australia. Aust Vet J 2016 AUG;94(8):273-273.

(78) Oda S, Kabeya H, Sato S, Shimonagane A, Inoue K, Hayashidani H, et al. Isolation of pathogenic Yersinia enterocolitica 1B/O:8 from Apodemus mice in Japan. J Wildl Dis 2015 JAN;51(1):260-264.

(79) Platt-Samoraj A, Syczylo K, Szczerba-Turek A, Bancerz-Kisiel A, Jablonski A, Labuc S, et al. Presence of ail and yst $\mathrm{B}$ genes in Yersinia enterocolitica biotype 1A isolates from game animals in Poland. Vet J 2017 MAR;221:11-13.

(80) Nakamura S, Hayashidani H, Okabe N, Une Y. Aberrant forms of Yersinia pseudotuberculosis as spheroplasts and filaments in yersiniosis in squirrel monkeys. Vet Pathol 2015 MAR;52(2):393396.

(81) Galosi L, Farneti S, Rossi G, Cork SC, Ferraro S, Magi GE, et al. Yersinia pseudotuberculosis, serogroup O:1a, infection in two amazon parrots (Amazona aestiva and Amazona oratrix) with hepatic hemosiderosis. J Zoo Wildl Med 2015 SEP;46(3):588-591.

(82) Nakamura S, Hayashidani H, Sotohira Y, Une Y. Yersiniosis caused by Yersinia pseudotuberculosis in captive toucans (Ramphastidae) and a Japanese squirrel (Sciurus lis) in zoological gardens in Japan. J Vet Med Sci 2016 FEB;78(2):297-299.

(83) Stoute ST, Cooper GL, Bickford AA, Carnaccini S, Shivaprasad HL, Sentíes-Cué CG. Yersinia pseudotuberculosis in Eurasian collared doves (Streptopelia decaocto) and retrospective study of avian yersiniosis at the California animal health and food safety laboratory system (1990-2015). Avian Dis 2016;60(1):82-86.

(84) Nakamura S, Hayashidani H, Yonezawa A, Suzuki I, Une Y. Yersiniosis due to infection by Yersinia pseudotuberculosis $4 \mathrm{~b}$ in captive meerkats (Suricata suricatta) in Japan. J Vet Diagn Invest 2015 SEP;27(5):641-644. 
511 Table 1

512 Housekeeping genes used for multilocus sequence analysis (MLSA) and typing (MLST) of Yersinia 513 spp.

\begin{tabular}{|c|c|c|c|c|}
\hline \multirow[t]{2}{*}{ Genes } & \multirow[t]{2}{*}{ MLSA } & \multicolumn{2}{|c|}{ MLST applied mostly for } & \multirow[t]{2}{*}{ References } \\
\hline & & $\begin{array}{l}\text { Yersinia } \\
\text { enterocolitica }\end{array}$ & $\begin{array}{l}\text { Yersinia } \\
\text { pseudotuberculosis }\end{array}$ & \\
\hline $\operatorname{aarF}$ & & $\mathrm{x}$ & & $(5,34,57)$ \\
\hline$a d k$ & & & $\mathrm{x}$ & $(16,26,39,58,59)$ \\
\hline $\arg A$ & & & $\mathrm{x}$ & $(16,26,39,58,59)$ \\
\hline aroA & & & $\mathrm{x}$ & $(16,26,39,58,59)$ \\
\hline$d f p$ & & $\mathrm{x}$ & & $(5,34,57)$ \\
\hline galR & & $\mathrm{X}$ & & $(5,34,57)$ \\
\hline$g \ln A$ & $\mathrm{X}$ & & $\mathrm{x}$ & $(11,15,16,26,39,53-55,58,59)$ \\
\hline$g \ln S$ & & $\mathrm{x}$ & & $(5,34,57)$ \\
\hline gyrB & $\mathrm{x}$ & & & $(11,15,16,47,53-55)$ \\
\hline hemA & & $\mathrm{x}$ & & $(5,34,57)$ \\
\hline hsp60 & $\mathrm{x}$ & & & $(11,15,47,53-55)$ \\
\hline recA & $\mathrm{x}$ & & & $(11,15,53-55)$ \\
\hline$r f a E$ & & $\mathrm{x}$ & & $(5,34,57)$ \\
\hline rров & $\mathrm{x}$ & & & $(47)$ \\
\hline $\operatorname{sod} A$ & $\mathrm{x}$ & & & (47) \\
\hline speA & & $\mathrm{x}$ & & $(5,34,57)$ \\
\hline thrA & & & $\mathrm{x}$ & $(16,26,39,58,59)$ \\
\hline tmk & & & $\mathrm{x}$ & $(26,39,58,59)$ \\
\hline $\operatorname{trp} E$ & & & $\mathrm{x}$ & $(16,26,39,58,59)$ \\
\hline
\end{tabular}


515 Table 2

516 Recently identified pathogenic Yersinia enterocolitica (YE) and Yersinia pseudotuberculosis (YP)

517 in various animal sources.

\begin{tabular}{|c|c|c|c|c|c|}
\hline Animals & YE & $\mathrm{YP}$ & $\mathrm{BT} / \mathrm{ST}$ & Country & Referenck18 \\
\hline Captive meerkats & & $\mathrm{x}$ & $\mathrm{O}: 4$ & Japan & (84) \\
\hline Captive monkeys & & $\mathrm{x}$ & $\mathrm{O}: 1, \mathrm{O}: 4, \mathrm{O}: 6$ & Japan & (80) \\
\hline Captive squirrels & & $\mathrm{x}$ & $0: 1$ & Japan & (82) \\
\hline Captive toucans & & $\mathrm{x}$ & $\mathrm{O}: 2, \mathrm{O}: 4$ & Japan & (82) \\
\hline Cattle & $\mathrm{x}$ & & O:9 & Ireland, Poland & $(61,62)$ \\
\hline Chickens & $\mathrm{x}$ & & $3 / \mathrm{O}: 3$ & China & (32) \\
\hline Dogs & $\mathrm{x}$ & & $3 / \mathrm{O}: 3$ & China & (32) \\
\hline Goats & $\mathrm{x}$ & & $3 / \mathrm{O}: 3$ & China & (32) \\
\hline Pet hamsters & $\mathrm{x}$ & & $3 / \mathrm{O}: 3$ & Japan & (75) \\
\hline Pet parrots & & $\mathrm{x}$ & O:1 & Italy & (81) \\
\hline \multirow[t]{9}{*}{ Pigs } & $\mathrm{x}$ & & 4/O:3 & Africa & (36) \\
\hline & $\mathrm{x}$ & & 2/O:9, 3/O:3 & China & (32) \\
\hline & $\mathrm{x}$ & & $0: 3$ & Croatia & (71) \\
\hline & $\mathrm{x}$ & & $4 / O: 3$ & Finland & (73) \\
\hline & $\mathrm{x}$ & & 4/O:3 & Italy & (19) \\
\hline & & $\mathrm{x}$ & $\mathrm{O}: 1, \mathrm{O}: 3$ & Italy & (19) \\
\hline & $\mathrm{x}$ & & $4 / 0: 3$ & Netherlands & (72) \\
\hline & & $\mathrm{x}$ & $\mathrm{O}: 1, \mathrm{O}: 2$ & Netherlands & (72) \\
\hline & $\mathrm{x}$ & & 4/O:3, 2/O5,27, 2/O:9 & Turkey & $(51)$ \\
\hline \multirow[t]{2}{*}{ Sheep } & $\mathrm{x}$ & & 2/O:9, 5/O:(1,2,)3 & Finland & (30) \\
\hline & & $\mathrm{x}$ & $0: 1$ & Italy & (24) \\
\hline Shrews & & $\mathrm{x}$ & $\mathrm{O}: 2$ & Finland & (29) \\
\hline Voles & $\mathrm{x}$ & & $2 / \mathrm{O}: 9$ & Finland & (29) \\
\hline \multirow[t]{2}{*}{ Wild boars } & & $\mathrm{x}$ & $\mathrm{O}: 1$ & Spain & $(65)$ \\
\hline & $\mathrm{x}$ & & $4 / 0: 3$ & Poland & (28) \\
\hline \multirow[t]{4}{*}{ Wild rodents } & $\mathrm{x}$ & & 2/O:5,27, 3/O:1,2,3 & Belgium & (33) \\
\hline & & $\mathrm{x}$ & $\mathrm{O}: 1$ & Belgium & (33) \\
\hline & $\mathrm{x}$ & & $1 \mathrm{~B} / \mathrm{O}: 8$ & Japan & (78) \\
\hline & $\mathrm{x}$ & & $2 / \mathrm{O}: 9,3 / \mathrm{O}: 3$ & China & (32) \\
\hline
\end{tabular}

